\title{
A firm grip does not always pay off: a new Phact(r) 4 integrin signaling
}

\author{
Zhiqi Sun and Reinhard Fässler ${ }^{1}$ \\ Department of Molecular Medicine, Max Planck Institute of Biochemistry, Martinsried 82152, Germany
}

\begin{abstract}
$\beta 1$ integrin signaling plays crucial roles in enteric nervous system development. Zhang and colleagues (pp. 69-81) discovered that phosphatase and actin regulator 4 (Phactr4) antagonizes $\beta 1$ integrin signaling through protein phosphatase 1 (PP1) in focal adhesions of enteric neural crest cells (ENCCs). Loss of Phactr4-PP1 interaction leads to increased $\beta 1$ integrin signaling, loss of collective and directional migration, and hindgut hypogangaliosis, indicating that the right adjustment of $\beta 1$ integrin signaling is required for the normal migration and organization of ENCCs.
\end{abstract}

Hirschsprung disease (HSCR; also called congenital aganglionic megacolon) is a congenital disorder of the distal colon in which the enteric nervous system (ENS) is absent (Brooks et al. 2005). The lack of the enteric neurons leads to a contracted colon, which prevents peristaltic movements of the intestine and obstructs the passage of food residue. The cause for the absent ENS can be due to impaired proliferation, differentiation, or migration of enteric neural crest cells (ENCCs) into the distal colon and rectum (Heanue and Pachnis 2007). ENS development commences at around embryonic days 9-9.5 (E9-E9.5) in mice, when vagal neural crest cells emigrate from the neural tube and invade the foregut (Newgreen and Young 2002). From the foregut, they migrate as ENCCs in a rostrocaudal direction to colonize the developing gastrointestinal tract. When the gastrointestinal tract is colonized, the ENCCs differentiate into different subtypes of neurons and glia, which organize into ganglia and finally interconnect to form the mature ENS (Fig. 1). The differentiation and migration of ENCCs are orchestrated by chemoattractants such as Glial cell line-derived neurotrophic factor (GDNF) and endothelin 3 and their cognate receptors, RET and endothelin-B receptors, respectively (Hearn et al. 1998; Young et al. 2001; Barlow et al. 2003; Burzynski et al. 2009).

The migration of ENCCs has been studied by timelapse video microscopy in gut explants derived from

[Keywords: directional cell migration; enteric neural crest cell; Hirschsprung disease; Phactr4; PP1; $\beta 1$ integrin; cofilin]

${ }^{1}$ Corresponding author.

E-mail: faessler@biochem.mpg.de.

Article is online at http://www.genesdev.org/cgi/doi/10.1101/gad.184192.111. transgenic mice expressing fluorescent reporter genes in neural crest cells. These studies revealed several intriguing features of their complex migration behavior. ENCCs form long chains in which the cells are tightly connected via cell-cell adhesion (Young et al. 2004). At the migratory wave front of these cell chains are a few solitary cells, also called advanced cells. They detach from the cell chains, explore the environment by continuously protruding their plasma membranes, and aid the forward migration of the following chain of cells (Druckenbrod and Epstein 2005, 2007). ENCCs migrate along most of the gastrointestinal tract with a net migration speed of $\sim 30$ $40 \mu \mathrm{m}$ per hour (Young et al. 2004; Druckenbrod and Epstein 2005). When they reach the junction with the caecum, they pause for $\sim 8-12 \mathrm{~h}$. During this period, the migrating chains dissociate into single cells, which move into the caecum, where they show a rapid and nondirectional migration behavior (Druckenbrod and Epstein 2005). Once they have reached the colon, they rejoin into cell chains, form advanced cells at the wave front, and resume the usual migratory mode. The exact reason for the switch of the migratory mode in the caecum is not known. However, it is likely due to the unique signaling and tissue environment of the caecum (Heanue and Pachnis 2007). For instance, the caecum is tremendously rich in extracellular matrix (ECM) proteins such as fibronectin (FN). FN binds to $\beta 1$ integrins, which were shown to be essential for the migration of ENCCs (Breau et al. 2009).

Integrins are the major cell adhesion molecules for the ECM. They are heterodimeric transmembrane receptors consisting of an $\alpha$ and a $\beta$ subunit. The human and mouse proteomes contain $18 \alpha$ and eight $\beta$ subunits, which can assemble into 24 different integrin heterodimers, each binding to a specific set of ECM proteins (Humphries et al. 2006). A hallmark of integrins is that they must change their conformation before they can bind their ECM ligand (Moser et al. 2009). Following ligand binding, integrins cluster and recruit signaling, adaptor, and actin-binding molecules to their cytoplasmic domains, which results in the coupling of the ECM to the actin cytoskeleton and the formation of a large signaling hub known as focal adhesion (FA) (Geiger et al. 2009). Integrin signaling is finely tuned to control a large number of biological processes, including directional and persistent cell migration. To achieve this, integrins regulate the subcellular activity of small RhoGTPases, which are essential for the dynamic 


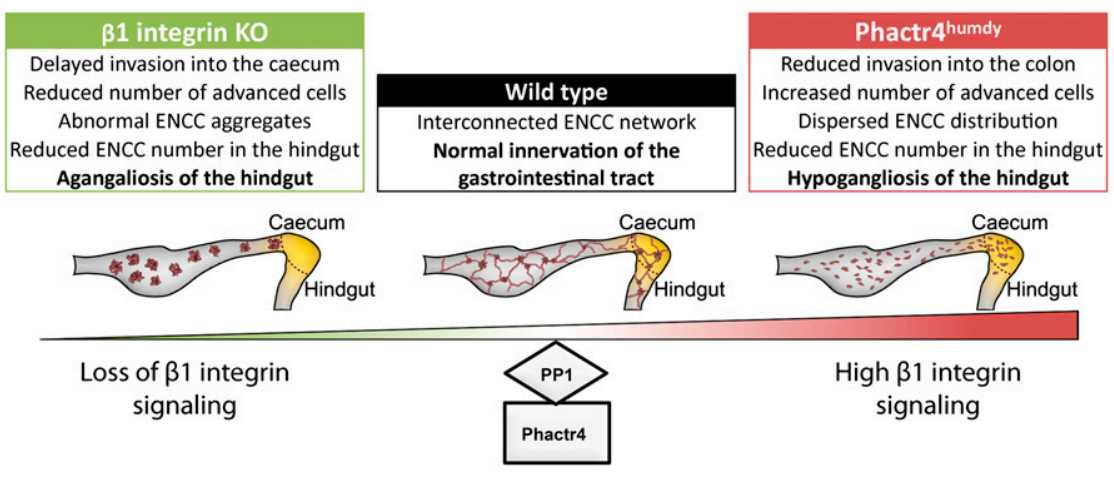

Figure 1. Physiologic $\beta 1$ integrin signaling is required for the normal migration and organization of ENCCs. The collective migration ENCCs in cell chains establishes an interconnected network, which resembles the organization of the ganglia and the interconnecting neurites of the mature ENS. While the $\beta 1$ integrin gene ablation leads to abnormal ENCC aggregates and delayed invasion of the caecum, the Phactr4 ${ }^{\text {humdy }}$ mutation leads to increased $\beta 1$ integrin signaling, dissociation of ENCCs, loss of collective migration, and hindgut hypogangaliosis. formation of a stable and persistent lamellipodium at the leading edge of a migrating cell, and adjust the activity of actin-modulating proteins, including actin nucleators such as formins or the Arp2/3 complex, filamentous actin (F-actin)-severing proteins such as cofilin, and others (Petrie et al. 2009). It is important to note that diminished as well as elevated signaling by integrins can lead to pathology. This is nicely demonstrated in mice with decreased and increased $\beta 1$ integrin function (Bouvard et al. 2007; Legate et al. 2009; Rantala et al. 2011).

The $\beta 1$ integrin subunit can associate with $12 \alpha$ subunits and thus forms the largest integrin subfamily. Constitutive deletion of the $\beta 1$ integrin gene leads to peri-implantation lethality in mice (Fassler and Meyer 1995). Deletion of the $\beta 1$ integrin gene in neural crest cells affects the formation of multiple neural crest-dependent structures, including the ENS, leading to a HSCR-like phenotype with agangaliosis of the distal part of the colon (Fig. 1; Breau et al. 2006). The ENS defects are due to impaired migration and the formation of abnormal aggregates of ENCCs in the distal midgut, caecum, and hindgut. The major requirement for $\beta 1$ integrin expression for ENCCs becomes apparent when the migration pauses, and they should dissociate and invade the caecum and the adjacent hindgut. The $\beta 1$-null ENCCs remain abnormally aggregated and show reduced migration speed and persistence, resulting in diminished colonization of the rostral hindgut with ENCCs and a complete absence in the caudal hindgut (Breau et al. 2009). The migration defect of $\beta 1$-null ENCCs has not been well studied so far, but it is believed that several factors contribute to the defective hindgut colonization. An abnormal activation of small RhoGTPases through reduced adhesion to $\mathrm{FN}$ is most likely the major cause for the impaired migration machinery of $\beta 1$-null ENCCs. Furthermore, due to the delayed invasion of the caecum and the hindgut, the $\beta 1$-null ENCCs are believed to meet a growing and differentiating environment that is no longer permissive for incoming ENCCs to migrate efficiently and thus may prevent them from reaching the caudal hindgut. Finally, it has been shown that the density of ENCCs correlates with the efficiency of their own migration (Druckenbrod and Epstein 2005). Therefore, the reduced number of $\beta 1$-null ENCCs and their clustering in aggregates may also contribute to their failure to reach the rectum. These observations demonstrate that the loss of $\beta 1$ integrin expression severely compromises the migration of ENCCs and the formation of a functional ENS. In this issue of Genes \& Development, Zhang et al. (2012) report that phosphatase and actin regulator 4 (Phactr4), a novel adaptor protein, is present in FAs of ENCCs, where it antagonizes $\beta 1$ integrin signaling and diminishes the activity of the actin-severing protein cofilin. Consequently, impairing Phactr4 function in mice leads to increased $\beta 1$ integrin signaling in their ENCCs, resulting in severe defects in their migration and colonization of the hindgut.

The Phactr family of proteins consists of four members (Phactr1-4). They were initially identified as protein phosphatase 1 (PP1)-binding proteins in a yeast-two-hybrid screen (Allen et al. 2004). In addition to the C-terminal PP1-binding domain, all four proteins contain three RPEL repeats, which are actin-binding motifs (Miralles et al. 2003). Since immunoprecipitation of Phactr1, Phactr3 (also known as Scapinin), and Phactr4 brings down actin from the soluble fraction of a cell lysate (Allen et al. 2004; Kim et al. 2007; Sagara et al. 2009), it is believed that Phactr proteins bind G-actin. All four members are expressed in the mouse brain; however, each isoform has a distinct distribution and is found in different subcellular compartments (Sagara et al. 2003; Allen et al. 2004; Farghaian et al. 2011). Data on the in vivo functions of these proteins are scarce. In a forward genetic screen for neural tube closure defects in mice, Niswander and colleagues (Kim et al. 2007) identified a R650P missense mutation in Phactr4, which they called humdy (Phactr4 ${ }^{\text {humdy }}$ ). The R650P mutation disrupts PP1 binding to Phactr4 and leads to an inhibitory phosphorylation of PP1 at Thr 320 (Fig. 2) and loss of PP1 activity toward the retinoblastoma protein $(\mathrm{Rb})(\mathrm{Kim}$ et al. 2007). In the current study, Zhang et al. (2012) report that mice with a homozygous Phactr $4^{\text {humdy }}$ mutation develop a HSCRlike phenotype (Fig. 1). In the majority of Phactr4 ${ }^{\text {humdy }}$ mutant mice, the number of enteric neurons was normal, but they were individually distributed in the stomach, foregut, and midgut, instead of clustered in ganglia, and the neurites were disorganized. The hindgut of Phactr4 ${ }^{\text {humdy }}$ mutant mice contained fewer neurons, which were also abnormally distributed and without interconnected neurites. In rare cases, neural crest cell invasion of the entire bowel was abolished. Using gut explants combined with time-lapse video microscopy, Zhang et al. (2012) showed that the migration behavior of Phactr4 ${ }^{\text {humdy }}$ ENCCs is 
A

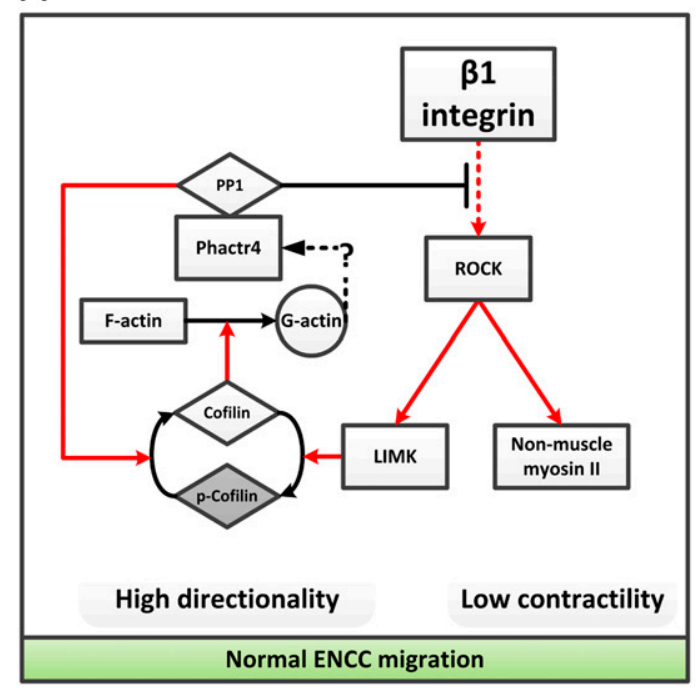

B

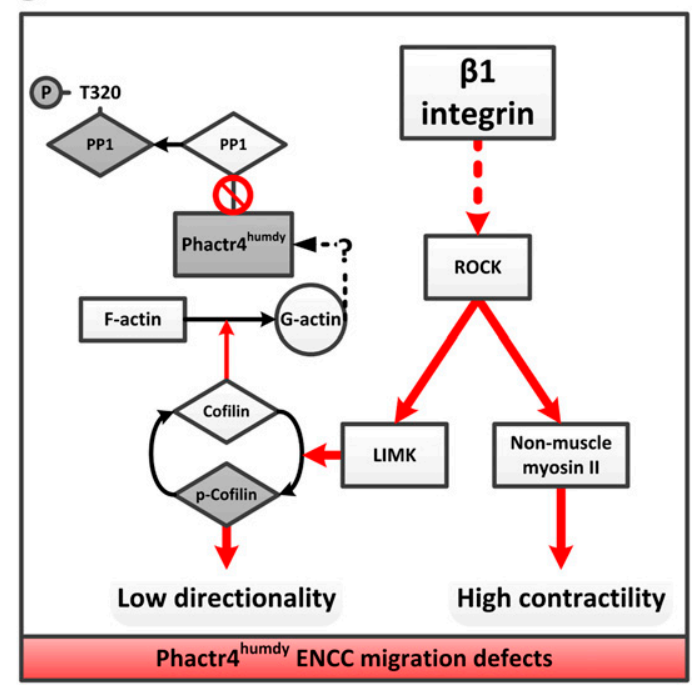

Figure 2. (A) Role of the Phactr4-PP1 complex in normal ENCCs. $\beta 1$ integrin signaling can activate ROCK through multiple, although not completely understood, pathways. ROCK, in turn, activates nonmuscle myosin II (NMII) and LIMK, which promotes the phosphorylation and subsequent inactivation of cofilin. Phactr4 interacts with PP1 and activates its phosphatase activity. The enhanced PP1 activity has two consequences: PP1 directly dephosphorylates and activates cofilin, and PP1 antagonizes $\beta 1$ integrin signaling (and thus ROCK activation) through unknown mechanisms. The reduced ROCK activity leads to reduced activation of NMII and decreased inactivation of cofilin. The reduced NMII activity dampens the contractility of ENCCs, and the increased cofilin activity enhances directional migration of ENCCs. The increased cofilin activity also liberates G-actin, which can bind Phactr4 and may thereby regulate the functional properties of the Phactr4-PP1 complex in a putative feedback loop. $(B)$ Misregulation of PP1 in Phactr $4{ }^{\text {humdy }}$ cells. Loss of the interaction between Phactr4 and PP1 in the Phactr4 ${ }^{\text {humdy }}$ mutant mice leads to decreased and misregulated PP1 activity. Consequently, cofilin is not inactivated and the $\beta 1$ integrin signaling pathway is not blocked, resulting in the loss of directional migration and increased cell contractility. In both panels, solid red arrows indicate direct activation between proteins; solid black arrows indicate a shift in protein activity (active/inactive cofilin, PP1, and Phactr4) or state (F-actin/G-actin); dotted red arrows indicate an unknown, multistep activation process; dotted black arrows indicate a putative feedback loop; and white protein boxes represent active proteins, while gray boxes represent inactive proteins.

abnormal and is responsible for the aberrant formation of the ENS. The normal number of ENCCs in the foregut and midgut and the reduced number in the hindgut suggests that Phactr4 $4^{\text {humdy }}$ ENCCs may have a defect in exiting the caecum and resuming collective chain migration in the adjacent hindgut. This possibility, however, was not tested, but could be analyzed and confirmed with graft assays.

Zhang et al. (2012) excluded defective proliferation or differentiation of ENCCs as the cause for the HSCR-like phenotype and showed with several imaging experiments that the collective and directional migration of Phactr $4{ }^{\text {humdy }}$ ENCCs was abnormal. Imaging ENCC migration in hindgut explants revealed that the Phactr4 4 humdy ENCCs lost their ability to form chains and to migrate in the caudal direction. Instead, they moved as single cells, which showed an erratic and nondirectional migration behavior. When the gut explants were embedded in collagen gels, the invasion of Phactr4 ${ }^{\text {humdy }}$ ENCCs into the collagen gel could be triggered by exogenous GDNF, albeit with lower efficiency when compared with wild-type cells, suggesting that the Phactr4 ${ }^{\text {humdy }}$ mutation abrogates the migration machinery of ENCCs rather than the ability to respond to a GDNF gradient. This hypothesis was confirmed with mouse embryonic fibroblasts (MEFs) from Phactr $4^{\text {humdy }}$ mutant mice that generate multiple retraction fibers and highly dynamic and unstable lamellipodia when cultured in two dimensions. Clearly, such erratic membrane protrusions and increased cell contractility can account for the loss in directionality.

How could the Phactr4-PP1 complex regulate migration of ENCCs at the molecular level? Experimental results by Zhang et al. (2012) indicate that in Phactr4 ${ }^{\text {humdy }}$ cells, PP1 activity is diminished and/or misregulated, $\beta 1$ integrin and Rho kinase (ROCK) activities are high, and cofilin is hyperphosphorylated at Ser 3 (likely through ROCKmediated LIMK activation), which leads to a diminished severing of F-actin. These findings suggest that PP1 activation through binding to Phactr4 in wild-type cells antagonizes $\beta 1$ integrin-ROCK-cofilin signaling to enhance cofilin activity and thereby promotes directional migration by maintaining a polarized actin cytoskeleton (Fig. 2). Consistent with a requirement of an active PP1 for persistent directional cell migration, chemical inhibition of PP1 induced a migration defect in wild-type ENCCs of gut tissue explants and in wild-type MEFs that closely resembled the defects observed with Phactr4 ${ }^{\text {humdy }}$ cells. In both cultured MEF cells and gut tissue explants, functional blockade of $\beta 1$ integrins using antibodies or RGD peptides or by inhibition of ROCK rescued the migration defect. Strikingly, blocking $\beta 1$ integrin function in gut tissue explants largely restored the collective migration ENCCs and the net speed of the forward-moving wave front. This 
observation strongly suggests that $\beta 1$ integrin activity needs to be down-regulated, particularly when ENCCs invade the hindgut and are exposed to a change in FN concentration to resume chain migration. One crucial question is at which point Phactr4-PP1 intersects with $\beta 1$ integrin-ROCK-cofilin signaling. Another unanswered question is how Phactr4-PP1 controls cell contractility. It has been shown that overexpression of constitutively active LIMK (which can phosphorylate cofilin) or phospho-mimicking mutants of cofilin disrupts cell polarity by inducing the formation of multiple lamellipodia (Dawe et al. 2003). However, cofilin does not directly interfere with cell contractility. Contraction along F-actin filaments is mainly mediated by nonmuscle myosin II (NMII) in nonmuscle cells (Vicente-Manzanares et al. 2009). PP1 is the major phosphatase that dephosphorylates myosin regulatory light chain (MRLC) (Matsumura and Hartshorne 2008). On the other hand, it is well known that ROCK activates NMII by phosphorylating the MRLC. ROCK also reduces the activity of PP1 toward MRLC by phosphorylating myosin phosphatase-targeting subunit 1 (Totsukawa et al. 2000). Since chemical inhibition of ROCK restored lamellipodia formation in Phactr4 ${ }^{\text {humdy }}$ cells, it is conceivable that Phactr4-PP1 regulates integrin signaling upstream of cofilin. However, since ROCK inhibition only partially rescued the collective migration of Phactr 4 humdy mutant ENCCs, it is likely that Phactr4 also regulates other signaling events downstream from $\beta 1$ integrin through either controlling PP1 activity or other unknown mechanisms (Fig. 2).

PP1 is a ubiquitously expressed serine/threonine phosphatase that regulates many biological processes, including cell survival, cell division, metabolism, and cytoskeletal reorganizations (Cohen 2002). PP1 consists of a catalytic and a regulatory subunit. There are three isoforms of PP1 catalytic subunits: PP1 $\alpha, \mathrm{PP} 1 \beta$, and PP1 $\gamma$. The recruitment of the catalytic subunit of PP1 to regulatory subunits determines the subcellular localization and the substrate specificity of PP1 (Shi 2009). For instance, the actin-binding regulatory subunit spinophilin targets PP1 to actin filaments and cell-cell junctions (Satoh et al. 1998), where it also blocks potential substrate-binding sites on the catalytic subunit and thereby increases substrate specificity (Ragusa et al. 2010). Notably, Phactr4 can interact with all PP1 family members, making Phactr4 a potent and multifunctional regulator of PP1 signaling (Kim et al. 2007). Actin binding by Phactr proteins could add another level of complexity. Biochemical analysis has shown that Phactr proteins interact with G-actin through RPEL repeats. Consistent with this finding, the localization of overexpressed Phactr4 is largely reciprocal with actin stress fibers. The interaction between Phactr and G-actin is likely to reduce actin polymerization in cell protrusions (Sagara et al. 2009). Furthermore, it is currently not known whether G-actin and PP1 binding to Phactr4 are mutually exclusive, synergistic, or independent. Since RPEL repeats abut the PP1 binding domain, it is possible that actin binding to the RPEL repeats might compete with the PP1 recruitment through steric hindrance. Low G-actin concentration might thus lead to the formation of Phactr4-PP1 complexes, which could then activate cofilin to increase the G-actin pool. In such a scenario, Phactr4 could serve as a feedback regulator that senses actin dynamics and modulates PP1 activity accordingly (Fig. 2). To further clarify these issues, structural analysis of the actin-Phactr-PP1 complex will be needed.

The subcellular localization Phactr4 is likely important to locally regulate PP1 activity. Endogenous Phactr4 colocalizes with $\beta 1$ integrin in mature FAs of MEFs seeded on FN. Whether it also localizes to other subcellular compartments such as cell-cell adhesion sites has not been investigated so far. The immunolocalization of Phactr4 in FAs makes Phactr4 a novel FA protein. Interestingly, Phactr $4^{\text {humdy }}$ is also recruited to FAs, indicating that its recruitment does not require the interaction with PP1. FAs have a complex protein composition and an intricate molecular organization and are highly dynamic. As with all classic signaling centers, kinases are abundant in FAs, and many FA proteins become phosphorylated at multiple sites. How PP1 activity is controlled to balance the phosphorylation state of its target proteins and how it achieves substrate specificity in this compartment are not understood. Many potential PP1 regulatory partners have been found. Besides tensin (Eto et al. 2007), PINCH1 has recently been identified as a regulator of PP1 $\alpha$ in FAs (Eke et al. 2010). PINCH is a constitutive component of the integrin-linked kinase, PINCH, and parvin (IPP) complex (Legate et al. 2006). $\mathrm{PINCH}$ interacts through a consensus PP1 interaction motif in its fifth LIM domain with $\mathrm{PP} 1 \alpha$, but not with the two other isoforms. This interaction inhibits the activity of PP1 $\alpha$ against Akt1 and regulates cell survival (Eke et al. 2010). Since the IPP complex is crucial for $\beta 1$ integrin-mediated cell motility and adhesion, it is possible that Phactr4 might also regulate $\beta 1$ integrin signaling by competing with $\mathrm{PINCH}$ for PP1 $\alpha$ binding. Reciprocally, PINCH binding to PP1 $\alpha$ might shift the binding of Phactr 4 to other PP1 isoforms and thus modulate the activity and substrate specificity of the Phactr4-PP1 complex.

In conclusion, the work on Phactr4 gives a new flavor to our understanding of how $\beta 1$ integrin signaling is regulated at different stages of ENCC migration. But, as with all studies describing novel and exciting findings, the study by Zhang et al. (2012) also raises many new questions: How does the Phactr4-PP1 complex intersect with integrin signaling, and is cell-cell adhesion regulated directly by Phactr4-PP1 or indirectly through integrins? Is it possible that Phactr proteins control cell migration not only by regulating PP1 activity, but also by regulating actin dynamics via a feedback regulatory loop involving the binding to PP1 and G-actin? Finally, is the aberrant upregulation of phospho-cofilin the only known substrate of PP1 that disrupts cell polarity, or is the Phactr4 ${ }^{\text {humdy }}$ phenotype in ENCCs due to a combined dysregulation of many PP1 downstream targets? Time will surely give us the answers!

\section{Acknowledgment}

The work in the Fässler laboratory is funded by the Max Planck Society. 


\section{References}

Allen PB, Greenfield AT, Svenningsson P, Haspeslagh DC, Greengard P. 2004. Phactrs 1-4: A family of protein phosphatase 1 and actin regulatory proteins. Proc Natl Acad Sci 101: 7187-7192.

Barlow A, de Graaff E, Pachnis V. 2003. Enteric nervous system progenitors are coordinately controlled by the $\mathrm{G}$ proteincoupled receptor EDNRB and the receptor tyrosine kinase RET. Neuron 40: 905-916.

Bouvard D, Aszodi A, Kostka G, Block MR, Albiges-Rizo C, Fassler R. 2007. Defective osteoblast function in ICAP-1deficient mice. Development 134: 2615-2625.

Breau MA, Pietri T, Eder O, Blanche M, Brakebusch C, Fassler R, Thiery JP, Dufour S. 2006. Lack of $\beta 1$ integrins in enteric neural crest cells leads to a Hirschsprung-like phenotype. Development 133: 1725-1734.

Breau MA, Dahmani A, Broders-Bondon F, Thiery JP, Dufour S. 2009. $\beta 1$ integrins are required for the invasion of the caecum and proximal hindgut by enteric neural crest cells. Development 136: 2791-2801.

Brooks AS, Oostra BA, Hofstra RM. 2005. Studying the genetics of Hirschsprung's disease: Unraveling an oligogenic disorder. Clin Genet 67: 6-14.

Burzynski G, Shepherd IT, Enomoto H. 2009. Genetic model system studies of the development of the enteric nervous system, gut motility and Hirschsprung's disease. Neurogastroenterol Motil 21: 113-127.

Cohen PT. 2002. Protein phosphatase 1-targeted in many directions. J Cell Sci 115: 241-256.

Dawe HR, Minamide LS, Bamburg JR, Cramer LP. 2003. ADF/ cofilin controls cell polarity during fibroblast migration. Curr Biol 13: 252-257.

Druckenbrod NR, Epstein ML. 2005. The pattern of neural crest advance in the cecum and colon. Dev Biol 287: 125-133.

Druckenbrod NR, Epstein ML. 2007. Behavior of enteric neural crest-derived cells varies with respect to the migratory wavefront. Dev Dyn 236: 84-92.

Eke I, Koch U, Hehlgans S, Sandfort V, Stanchi F, Zips D, Baumann M, Shevchenko A, Pilarsky C, Haase M, et al. 2010. PINCH1 regulates Akt1 activation and enhances radioresistance by inhibiting PP1 $\alpha$. J Clin Invest 120: 2516-2527.

Eto M, Kirkbride J, Elliott E, Lo SH, Brautigan DL. 2007. Association of the tensin N-terminal protein-tyrosine phosphatase domain with the $\alpha$ isoform of protein phosphatase-1 in focal adhesions. J Biol Chem 282: 17806-17815.

Farghaian H, Chen Y, Fu AW, Fu AK, Ip JP, Ip NY, Turnley AM, Cole AR. 2011. Scapinin-induced inhibition of axon elongation is attenuated by phosphorylation and translocation to the cytoplasm. J Biol Chem 286: 19724-19734.

Fassler R, Meyer M. 1995. Consequences of lack of $\beta 1$ integrin gene expression in mice. Genes \& Dev 9: 1896-1908.

Geiger B, Spatz JP, Bershadsky AD. 2009. Environmental sensing through focal adhesions. Nat Rev Mol Cell Biol 10: 21-33.

Heanue TA, Pachnis V. 2007. Enteric nervous system development and Hirschsprung's disease: Advances in genetic and stem cell studies. Nat Rev Neurosci 8: 466-479.

Hearn CJ, Murphy M, Newgreen D. 1998. GDNF and ET-3 differentially modulate the numbers of avian enteric neural crest cells and enteric neurons in vitro. Dev Biol 197: 93-105.

Humphries JD, Byron A, Humphries MJ. 2006. Integrin ligands at a glance. J Cell Sci 119: 3901-3903.

Kim TH, Goodman J, Anderson KV, Niswander L. 2007. Phactr4 regulates neural tube and optic fissure closure by controlling PP1-, Rb-, and E2F1-regulated cell-cycle progression. Dev Cell 13: $87-102$.
Legate KR, Montanez E, Kudlacek O, Fassler R. 2006. ILK, PINCH and parvin: The tIPP of integrin signalling. Nat Rev Mol Cell Biol 7: 20-31.

Legate KR, Wickstrom SA, Fassler R. 2009. Genetic and cell biological analysis of integrin outside-in signaling. Genes Dev 23: 397-418.

Matsumura F, Hartshorne DJ. 2008. Myosin phosphatase target subunit: Many roles in cell function. Biochem Biophys Res Commun 369: 149-156.

Miralles F, Posern G, Zaromytidou AI, Treisman R. 2003. Actin dynamics control SRF activity by regulation of its coactivator MAL. Cell 113: 329-342.

Moser M, Legate KR, Zent R, Fassler R. 2009. The tail of integrins, talin, and kindlins. Science 324: 895-899.

Newgreen D, Young HM. 2002. Enteric nervous system: Development and developmental disturbances-part 2. Pediatr Dev Pathol 5: 329-349.

Petrie RJ, Doyle AD, Yamada KM. 2009. Random versus directionally persistent cell migration. Nat Rev Mol Cell Biol 10: 538-549.

Ragusa MJ, Dancheck B, Critton DA, Nairn AC, Page R, Peti W. 2010. Spinophilin directs protein phosphatase 1 specificity by blocking substrate binding sites. Nat Struct Mol Biol 17: 459-464.

Rantala JK, Pouwels J, Pellinen T, Veltel S, Laasola P, Mattila E, Potter CS, Duffy T, Sundberg JP, Kallioniemi O, et al. 2011. SHARPIN is an endogenous inhibitor of $\beta 1$-integrin activation. Nat Cell Biol 13: 1315-1324.

Sagara J, Higuchi T, Hattori Y, Moriya M, Sarvotham H, Shima H, Shirato H, Kikuchi K, Taniguchi S. 2003. Scapinin, a putative protein phosphatase-1 regulatory subunit associated with the nuclear nonchromatin structure. I Biol Chem 278: 4561145619.

Sagara J, Arata T, Taniguchi S. 2009. Scapinin, the protein phosphatase 1 binding protein, enhances cell spreading and motility by interacting with the actin cytoskeleton. PLoS ONE 4: e4247. doi: 10.1371/journal.pone.0004247.

Satoh A, Nakanishi H, Obaishi H, Wada M, Takahashi K, Satoh K, Hirao K, Nishioka H, Hata Y, Mizoguchi A, et al. 1998. Neurabin-II/spinophilin. An actin filament-binding protein with one pdz domain localized at cadherin-based cell-cell adhesion sites. I Biol Chem 273: 3470-3475.

Shi Y. 2009. Serine/threonine phosphatases: Mechanism through structure. Cell 139: 468-484.

Totsukawa G, Yamakita Y, Yamashiro S, Hartshorne DJ, Sasaki Y, Matsumura F. 2000. Distinct roles of ROCK (Rho-kinase) and MLCK in spatial regulation of MLC phosphorylation for assembly of stress fibers and focal adhesions in 3T3 fibroblasts. J Cell Biol 150: 797-806.

Vicente-Manzanares M, Ma X, Adelstein RS, Horwitz AR. 2009. Non-muscle myosin II takes centre stage in cell adhesion and migration. Nat Rev Mol Cell Biol 10: 778-790.

Young HM, Hearn CJ, Farlie PG, Canty AJ, Thomas PQ, Newgreen DF. 2001. GDNF is a chemoattractant for enteric neural cells. Dev Biol 229: 503-516.

Young HM, Bergner AJ, Anderson RB, Enomoto H, Milbrandt J, Newgreen DF, Whitington PM. 2004. Dynamics of neural crest-derived cell migration in the embryonic mouse gut. Dev Biol 270: 455-473.

Zhang Y, Kim T-H, Niswander L. 2012. Phactr4 regulates directional migration of enteric neural crest through PP1, integrin signaling, and cofilin activity. Genes Dev (this issue). doi: 10.1101/gad.179283.111. 


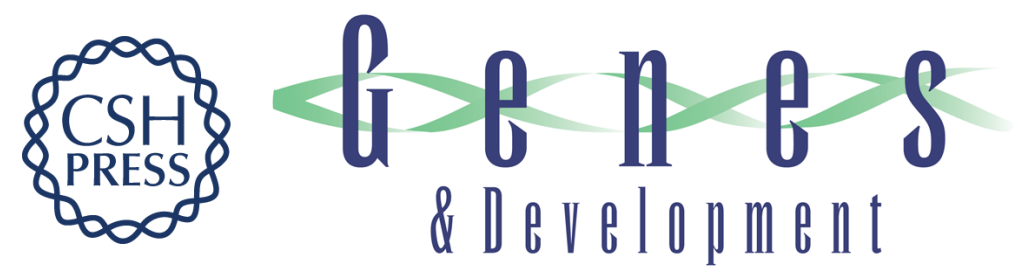

\section{A firm grip does not always pay off: a new Phact(r) 4 integrin signaling}

Zhiqi Sun and Reinhard Fässler

Genes Dev. 2012, 26:

Access the most recent version at doi:10.1101/gad.184192.111

Related Content Phactr4 regulates directional migration of enteric neural crest through PP1, integrin signaling, and cofilin activity

Ying Zhang, Tae-Hee Kim and Lee Niswander

Genes Dev. January, 2012 26: 69-81 Phactr4 Integrin Antagonism

Annalisa M. VanHook

Sci. Signal. January, 2012 5: ec12

References This article cites 37 articles, 14 of which can be accessed free at:

http://genesdev.cshlp.org/content/26/1/1.full.html\#ref-list-1

Articles cited in:

http://genesdev.cshlp.org/content/26/1/1.full.html\#related-urls

License

Email Alerting Receive free email alerts when new articles cite this article - sign up in the box at the top Service right corner of the article or click here.

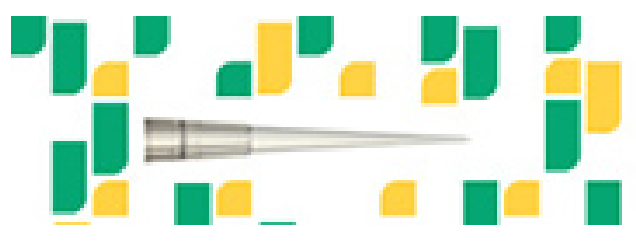

Focused on your science. 